\title{
Serum Lipid Profile in Preterm and Term Appropriate for Gestational Age Indian Newborns: A Hospital Based Comparative Study
}

Janardhan Shenoy, Venkat Reddy and Kiran N Baliga*

Kasturba Medical College, Manipal University, Mangalore, Karnataka, India

*Corresponding author: Baliga KN, Kasturba Medical College, Manipal University, Mangalore, Karnataka, India, Tel: 91-9886198991; E-mail: baligakiran@gmail.com Rec date: 25 Jun, 2014, Acc date: 17 Aug, 2014, Pub date: 19 Aug, 2014

Copyright: ( 2014 Shenoy J, et al. This is an open-access article distributed under the terms of the Creative Commons Attribution License, which permits unrestricted use, distribution, and reproduction in any medium, provided the original author and source are credited.

\begin{abstract}
Background: Cardiovascular disease is a common cause of death in developed countries and also is a rising trend in developing countries.

Aim: The objective of this study was to compare lipid profile and atherogenic indices in term and preterm neonates.

Methods: A total of 60 neonates were selected which were grouped on the basis of gestational age and birth weight. Umbilical venous blood was collected from them. Lipid profile (total cholesterol, LDL cholesterol, HDL cholesterol, VLDL cholesterol, triglycerides), apolipoproteins (apo B and apo A-I) and atherogenic index were evaluated and compared. Student- t test (unpaired) was applied to test the significance.

Results: Mean serum cholesterol and LDL was significantly high in preterm .Mean TC / LDL ratio of preterm group 3.17, term 2.64 ( $p<0.006)$. Mean Apolipoprotein A-1 in preterm $78.37 \mathrm{mg} / \mathrm{dl}$, term $76.51 \mathrm{mg} / \mathrm{dl}(\mathrm{P}<0.67)$. Mean apolipoprotein B / A-1 ratio in preterm 0.45, term 0.39, $(p<0.11)$ showing worse profile in preterm. Conclusions: These findings demonstrate a trend towards worse lipid profile in preterm SGA new-borns. There is a need to investigate if this atherogenic lipid profile is a marker for future cardiovascular diseases.
\end{abstract}

Keywords: Apolipoprotein A-1; Apolipoprotein B; Preterm; Cardiovascular Disease

\section{Introduction}

Cardiovascular disease is the primary cause of morbidity and mortality in developing countries. The incidence of coronary artery disease depends in general, on prevalence of genetic and environmental risk factors [1]. Recent animal experiments and human studies have shown the influence of intrauterine environment on the development of risk factors for cardiovascular disease [1]. These findings had led to the "fetal origin of cardiovascular disease," [2] which suggest that an adverse intrauterine environment during a critical period of development could program or imprint the development of fetal tissues and organs, and permanently determine responses that produce later dysfunction and disease [2]. It is known that premature newborns have lost the chance to complete their energy deposits in later part of pregnancy. Thus, many times these growth restricted neonates need to use endogenous reserves, thereby activating lipid metabolism that generates energy and promotes gluconeogenesis. Long-term consequences of these metabolic adaptations will leads to an increased prevalence of cardiovascular disease, hypertension and type 2 diabetes mellitus in this group of babies. Studies have shown that small for gestational age babies have abnormal lipid profile when compared to those normal for gestational age and these are the ones who are at risk of developing cardiovascular complications in the future. [1,3-6]. Hence this study was undertaken with an objective to compare lipid profile and atherogenic indices in term and preterm neonates.

\section{Study setting:}

The study was a Prospective; hospital based comparative study conducted from July 2008 to October 2009 conducted in Government Lady Goschen Hospital, Mangalore a tertiary referral centre affiliated to Kasturba Medical College, Mangalore with a 20 bedded neonatal intensive care unit.

\section{Methodology:}

A total of 60 inborn in the hospital were selected. Neonates were selected on the basis of gestational age ranging from 32-42 weeks and birth weight ranging from 1200-3800 grams. Birth weight was taken within $24 \mathrm{hrs}$ of birth on an electronic weighing machine. Gestational age was confirmed by New Ballard scoring system which was done within $24 \mathrm{hrs}$ of birth. Newborns were divided into two groups- term and preterm. Babies less than 37 completed weeks of gestation were taken as preterm and those with 37 completed weeks of gestation up to 42 weeks were taken as term. Neonates with congenital malformations, congenital heart diseases, hypoxia, respiratory distress syndrome, infants of diabetic mother, hypertension and myocardial diseases, thyroid diseases and hypercholesterolemia were excluded from the study. As per the inclusion criteria 30 term and 30 preterm babies were recruited for the study. Informed consent was obtained parents and institutional ethics committee. $2 \mathrm{ml}$ of Umbilical venous blood was collected in a clean, dry vial under aseptic precautions immediately after cord clamping, allowed to clot at room temperature and centrifuged to obtain serum. Serum was separated and used for determination of total cholesterol, Low Density LipoproteinCholesterol (LDL), High Density Lipoprotein-Cholesterol (HDL) by 
standard enzyme at ic methods. Apolipoprotein A-1, apolipoprotein B were measured by automated nephelometry method. Atherogenic indices like total cholesterol/HDL cholesterol, LDL cholesterol/HDL cholesterol, Apolipoprotein B/ apolipoprotein A-I were calculated.

\section{Statistical analysis:}

Data analysed using SPSS version 14. For statistical analysis students unpaired ' $\mathrm{t}$ ' test was used to compare them both groups and $\mathrm{p}$ value $<0.05$ was taken as statistically significant.

\section{Results}

Mean serum cholesterol of preterm newborns was $113.93 \mathrm{mg} / \mathrm{dl}$ whereas term newborns was $95.43 \mathrm{mg} / \mathrm{dl}$. $(\mathrm{P}<0.002)$ which was significant. Mean serum LDL of preterm newborns was $54.63 \mathrm{mg} / \mathrm{dl}$ whereas term newborns was $43.29 \mathrm{mg} / \mathrm{dl}(\mathrm{P}<0.031)$. Mean HDL levels in preterm was $36.73 \mathrm{mg} / \mathrm{dl}$, whereas in term was $37.63 \mathrm{mg} / \mathrm{dl}$. Total cholesterol / low density lipoprotein ratio is considered as one of the reliable risk factors for atherogenicity. Mean TC /HDL ratio of preterm group was 3.17, whereas in term group $2.64(\mathrm{p}<0.006)$. This was highly significant (Table 1). Mean LDL/HDL ratio of preterm was 1.53, whereas in term 1.16.TC / HDL ratio was high in preterm $(\mathrm{p}<0.028)$ which was significant (Table 1). Mean Apolipoprotein A-1in preterm was $78.37 \mathrm{mg} / \mathrm{dl}$, whereas in term $76.51 \mathrm{mg} / \mathrm{dl}(\mathrm{P}<0.67)$. Mean apolipoprotein $\mathrm{B}$ in preterm was35.52 $\mathrm{mg} / \mathrm{dl}$, whereas in term group $29.77 \mathrm{mg} / \mathrm{dl}, \quad(\mathrm{P}<0.11)$, even though statistically no significant difference, high levels in preterm group suggesting an unfavourable lipid profile in them(Table 2 ). Mean apolipoprotein B / A-1 ratio in preterm was 0.45 , whereas in term group was 0.39 , ( $p<0.11)$ showing unfavourable profile in preterm group.

\begin{tabular}{|l|l|l|l|}
\hline & $\begin{array}{l}\text { Preterm }(\mathbf{n}=\mathbf{3 0}) \\
\text { Mean +/- SD }\end{array}$ & $\begin{array}{l}\text { Term }(\mathbf{n}=\mathbf{3 0}) \\
\text { Mean +/- SD }\end{array}$ & 'p' value \\
\hline $\begin{array}{l}\text { Total } \\
\text { Cholesterol }\end{array}$ & $113.93+/-26.96$ & $95.43+/-15.44$ & 0.002 \\
\hline LDL & $54.63+/-24.71$ & $43.29+/-13.19$ & 0.031 \\
\hline HDL & $36.73+/-8.16$ & $37.63+/-7.92$ & 0.66 \\
\hline TC / HDL & $3.17+/-0.89$ & $2.64+/-0.51$ & 0.006 \\
\hline LDL / HDL & $1.53+/-0.78$ & $1.16+/-0.41$ & 0.028 \\
\hline
\end{tabular}

Table 1: Comparison of serum cholesterol and other atherogenic Indices

\begin{tabular}{|l|l|l|l|}
\hline & $\begin{array}{l}\text { Preterm }(\mathbf{n}=\mathbf{3 0}) \\
\text { Mean +/- SD }\end{array}$ & $\begin{array}{l}\text { Term }(\mathbf{n = 3 0}) \\
\text { Mean +/- SD }\end{array}$ & 'p' value \\
\hline Apolipoprotien A1 & $78.37+/-17.12$ & $76.51+/-16.94$ & 0.674 \\
\hline Apolipoprotien B & $35.52+/-11.74$ & $29.77+/-15.75$ & 0.115 \\
\hline Apolipoprotien B/A1 & $0.45+/-0.15$ & $0.39+/-0.16$ & 0.116 \\
\hline
\end{tabular}

Table 2: Comparison of Serum Apolipoproteins.

Pardo et al. [7] did similar study in near term and term groups. Their findings demonstrated that total cholesterol, LDL-cholesterol fraction and atherogenic indices were significantly high in near term neonates compared with term infants, showing a trend towards a worse lipid profile in Brazilian near term infants. Their study showed lower apolipoproteinA-1 levels in preterm group, related to inverse cholesterol transport. In our study along with apoliprotein-B, apolipoproteinA-1 levels also high in preterm group but apolipoprotein-B/A1, which is considered as one of the best markers of risk for cardiovascular disease, is high in preterm group, even though statistically not significant.

\section{Discussion}

A similar study by Irving et al. [8] in low birth weight babies showed that babies born prematurely, whether or not they have intra uterine growth retardation, are predisposed to similar risks as adults. The long term consequences of the hypercholesterolemic ambient seen in premature newborns regarding fatty streak formation are still debated. Although the atherogenic process has been recognized as a paediatric problem since 1965 , the reversibility of the injuries in this early phase of life is highly questionable. Napoli et al. [9] described aortic fatty streak formation in human foetuses, probably enhanced by maternal and presumably foetal hypercholesterolemia. A new study published by the same authors [10] demonstrated the existence of lipid accumulation in the extra cranial arteries of aborted foetuses and preterm newborns, demonstrating the atherogenic response to a hypercholesterolemic environment. Ijzerman RG et al. [11] suggested that genetic factors account for the association of low birth weight with high levels of total cholesterol, LDL-cholesterol and apolipoprotein B. A recent study correlated low gestational age with abnormal retinal vascularization and increased blood pressure in adult women [12]. Chandrika et al reported that abnormal intrauterine milieu created by maternal changes during gestation may bear a profound impact on lipid metabolism in neonates, which may account for their differences in lipid profile and anthropometry at birth [13]. Our findings demonstrate that total cholesterol, LDL-cholesterol and atherogenic indices were significantly higher in preterm neonates compared with term infants, showing a trend to a worse lipid profile in preterm neonates. Future studies are needed to determine if this atherogenic profile in preterm neonate can affect body metabolism, increasing the risk for a cardiovascular diseases in adult life.

\section{Conclusion}

Hence, the data demonstrates that lipid profile and atherogenic indices were unfavorable in preterm newborns. Apolipoprotein-B and apolipoproteinB/A1 ratio also found high in preterm compared to term newborns. However a small size has been a limitation in this study. It may be interesting to see whether these susceptible neonates do remain at an increased risk for developing cardiovascular diseases in future.

\section{References}

1. Wang X, Cui Y, Tong X, Ye H, Li S (2007) Glucose and lipid metabolism in small-for-gestational-age infants at 72 hours of age. See comment in PubMed Commons below J Clin Endocrinol Metab 92: 681-684.

2. Kent L, Thornburg (2004) Fetal Origins of Cardiovascular Disease. American Academy of Pediatrics December: 527-534.

3. Rasa V, Paul C, Claire LM (2006) Long-term metabolic consequences of being born small for gestational age. Expert Review of Endocrinology and Metabolism: 439-447.

4. Jones JN, Gercel-Taylor C, Taylor DD (1999) Altered cord serum lipid levels associated with small for gestational age infants. See comment in PubMed Commons below Obstet Gynecol 93: 527-531. 
Citation: Shenoy J, Reddy V, Baliga KN (2014) Serum Lipid Profile in Preterm and Term Appropriate for Gestational Age Indian Newborns: A Hospital Based Comparative Study. J Neonatal Biol 3: 156. doi:10.4172/2167-0897.1000156

Page 3 of 3

5. Molina M, Casanueva V, Cid X, Ferrada MC, Pérez R, et al. (2000) [Lipid profile in newborns with intrauterine growth retardation]. See comment in PubMed Commons below Rev Med Chil 128: 741-748.

6. Swiet MD (2003) Cardiovascular risk factors in infancy and childhood, Chapter 70. In: Anderson RH, Baker EJ, Macratney FJ, Rigby ML, Shinebourne EA, Tynam Michael. Pediatric Cardiology. (5th Edn) (Churchil Livingstone, London): 1876-1878.

7. Pardo IM, Geloneze B, Tambascia MA, Barros-Filho AA (2005) Atherogenic lipid profile of Brazilian near term newborns. Braz J Med Biol Res. 38: 755-760

8. Irving RJ, Belton NR, Elton RA, Walker BR (2000) Adult cardiovascular risk factors in premature babies. See comment in PubMed Commons below Lancet 355: 2135-2136.

9. Napoli C, D'Armiento FP, Mancini FP, Postiglione A, Witztum JL, et al. (1997) Fatty streak formation occurs in human fetal aortas and is greatly enhanced by maternal hypercholesterolemia. Intimal accumulation of low density lipoprotein and its oxidation precede monocyte recruitment into early atherosclerotic lesions. See comment in PubMed Commons below J Clin Invest 100: 2680-2690.
10. Napoli C, Witztum JL, de Nigris F, Palumbo G, D'Armiento FP, et al. (1999) Intracranial arteries of human fetuses are more resistant to hypercholesterolemia-induced fatty streak formation than extracranial arteries. See comment in PubMed Commons below Circulation 99: 2003-2010.

11. IJzerman RG, Stehouwer CD, Van Weissenbruch MM, De Geus EJ, Boomsma DI (2001) Evidence for genetic factors explaining the association between birth weight and low-density lipoprotein cholesterol and possible intrauterine factors influencing the association between birth weight and high-density lipoprotein cholesterol: analysis in twins. See comment in PubMed Commons below J Clin Endocrinol Metab 86: 5479-5484.

12. Kistner A, Jacobson L, Jacobson SH, Svensson E, Hellstrom A (2002) Low gestational age associated with abnormal retinal vascularization and increased blood pressure in adult women. See comment in PubMed Commons below Pediatr Res 51: 675-680.

13. Chandrika DN, Vaibhav A, Dinesh MN (2013) Correlation of Cord Blood Lipid Heterogeneity in Neonates with Their Anthropometry at Birth. Indian J Clin Biochem. 28: 152-157. 